\title{
Gender Gaps in Administrative Positions: The Case of Selected Educational Institutions in Lusaka District, Zambia
}

\author{
Charity Muuma, Ferdinand Mwaka Chipindi* \\ Email address: \\ chamum19777@gmail.com (C. Muuma),ferdinand.chipindi@unza.zm (F. M. Chipindi) \\ ${ }^{*}$ Corresponding author
}

School of Education, Department of Educational Administration and Policy University of Zambia, Lusaka, Zambia

\section{To cite this article:}

Charity Muuma, Ferdinand Mwaka Chipindi. Gender Gaps in Administrative Positions: The Case of Selected Educational Institutions in Lusaka District, Zambia. International Journal of Secondary Education. Vol. 9, No. 1, 2021, pp. 1-9. doi: 10.11648/j.ijsedu.20210901.11

Received: December 12, 2020; Accepted: December 19, 2020; Published: January 12, 2021

\begin{abstract}
The vision of the National Gender Policy (NGP) was to achieve gender equity at all levels of decision making in the Zambian political economy. Institutions of higher learning occupy a significant role in the socio-economic development of Zambia and are critically affected by gender policy issues. The study was carried out to investigate the Gender gaps among Women and Men in Administrative positions: The case of Educational Institutions in Lusaka District, Zambia. The objectives that guided the study were: to assess the extent of gender gaps in administrative positions of selected educational institutions; identify the causes of gender gaps in managerial positions of established educational institutions, and ascertain the effect of gender gaps in the operations of selected academic institutions. This research employed both quantitative and qualitative survey research approaches, which followed a descriptive case study design. The sample consisted of seventy-eight (78) respondents. This comprised of forty-eight (48) administrative officers from six (6) educational institutions, that is eight (8), administrative officers, from each institution. At the same time, thirty (30) respondents were sampled from non-administrative officers, five (5) non-administrative officers were sampled from individual educational institutions. Purposive sampling and random sampling technique were used to sample the participants. A questionnaire and semi-structured interviews were used to collect data from the field. The study revealed the extent to which there are gender gaps in administrative positions of educational institutions is very significant. That is because the number of male administrative thirty-one (31) officers is almost double the numbers of female administrative seventeen (17) officers. The causes of gender gaps in administrative positions included; lack of clear policy on recruitment and promotion of administrative officers, lack of affirmative action during recruitment and promotion process, stereotyping of administrative positions, lack of confidence, limited role models, low level of education and administrative experience amongst females, and being overwhelmed with household responsibilities.
\end{abstract}

Keywords: Gender, Gender Gap, Administrative Position

\section{Introduction}

The problem of an imbalance between men and women in various areas, including administrative positions, is being faced worldwide. ILO reveals that at the global level, the distribution between the two genders in decision-making positions and administrative positions tends to favour men [18]. Women have been under-represented at all levels of administrative position and decision-making process, especially in the government and parliament sector. For example, a memorandum submitted to Parliament by the Zambia Association for Research and Development (ZARD) in 2011 on the status of women in decision making established that gender inequalities were noticed by the low representation of women in political and administrative governance, in that out of thirty-five (35) Permanent Secretaries, only seven (7) were female. Women are mostly recruited and concentrated in the lower echelons of institutions and are in occupations with low remunerations such as nursing, secretarial and clearing services [16]. In 
Zambia, like many other Sub Sahara African countries, gender imbalances which do not favour women exist in the socio-economic, cultural, and political spheres. These imbalances have prevented women from effectively contributing to and benefiting from the development process [17].

\subsection{Statement of the Problem}

Although the Government of the Republic of Zambia (GRZ) adopted and began implementing the 2003-2007 Strategic Plan of Action for the National Gender Policy, the extent to which the organisations, particularly institutions of higher learning or tertiary learning institutions had addressed the $30 \%$ representation at management /decision-making levels and administrative positions had mainly been uncertain. This uncertainty constituted a problem which this research aimed to address. For example, if the extent to which the measures in the NGP had been addressing gender inequality remained uncertain, several underlying genderrelated problems would be perpetuated. If this study is not done, we may not be in a position to make any substantial claims of achievements made from the stated policy actions, and we may not augment the policy.

Despite the adoption and the implementation of the 20032007 Strategic Plan of Action for the National Gender Policy, the extent of gender gaps in an administrative position in educational institutions and the effects of gender gaps in administrative positions is unknown. And, surprisingly, few scholars have directed their attention to the representation of women as minorities in public offices, and their studies have been on causes of gender gaps in decision-making. The relative lack of research, however, is mostly the result of researchers not focusing on gender-gaps in workplaces, particularly in educational institutions. Hence the need for this study.

\subsection{Purpose of the Study}

The study sought to investigate gender gaps among women and men in administrative positions a case of educational institutions in Lusaka district, Zambia.

\subsection{Research Objectives}

i. To assess the extent of gender gaps in administrative positions of selected educational institutions.

ii. To determine the causes of gender gaps in administrative positions of selected educational institutions.

iii. To establish the effect of gender gaps in the operations of selected educational institutions.

\subsection{Significance of the Study}

Firstly, the findings of this study could be useful to both the Ministry of General Education (henceforth, MoGE) and the Ministry of Higher Education (henceforth, MoHE). The findings may help the policymakers to know the current gender gaps in their ministries and the effects which such gender gaps have on effective and efficient operations of the schools. The findings of this research could also be useful to the Ministry of Gender, which is because the findings of this research will help the policymakers under this ministry to examine their impact on society. Finally, the findings of this study could be useful to the Ministry of Community Development and Social Security to know the ratios in which the opportunities are distributed amongst the members of society. For this reason, the policymakers will be able to identify the gender which requires more help, so that they can be assisted in meeting the basic needs of life.

\section{Literature Review}

According to a report conducted by the Organisation for Economic Cooperation and Development, sustainable development can only be achieved through long-term investments in economic, human and environmental capital [25]. At present, the female half of the world's human capital is undervalued and underutilised the world over. This meant that the input of the women towards development was not being enhanced. As a result, the type of development which is taking place is not gender-balanced. That is because most of the views which are being considered originate from the males in the organisations and countries at large. For instance, the needs of females cannot be the exact needs of males. Consequently, when the majority of females are left out on decision making, their needs are usually not recognised by the majority of male policymakers.

Adetunde and Akensina assert that in recent decades, a large share of economic growth in the Organisation for Economic Cooperation and Development (OECD) area has come from employing more women [1]. Since 1995, narrowing the gap between male and female employment rates has accounted for half of the increase in Europe's overall employment rate and a quarter of annual economic growth. It is estimated that if female employment were raised to the male rate, growth in gross the domestic product (GDP) would be substantial, particularly in countries such as Japan. Similarly, Bergmann, explains that a study in the United Kingdom found that the country could gain $2 \%$ of GDP by better harnessing women's skills $[2,3]$. Yet, Cuberes and Teignier examine that the rate of female participation in the labour force is significantly lower than that of men in all countries [10]. On average, in OECD countries, about $60 \%$ of women are employed. However, Daley-Harris explains that wide variations are stemming from social and economic factors as well as public policies [12]. And Energia claims that the employment gender gap is most pronounced in countries such as Turkey, Mexico, Italy and Greece, where less than $50 \%$ of women work [13]. Female employment rates are highest at over $70 \%$ in Iceland, Denmark, Norway, Sweden and Switzerland. This implies that gender imbalance in employment is higher in the least developed countries but lower in highly developed countries. It, therefore, means that gender imbalance is positively associated with how the resources and opportunities in the country are shared. A country that has a sound governance system and consequently a fair distribution of resources tend to 
have low gender imbalance, while a country with a weak governance system tends to have unbalanced distributions of resources, the majority of the country's resources are possessed by few citizens of the country, leaving the broader majority in poverty.

According to McKinsey, one of the leading causes of gender imbalance has been the traditional beliefs that females cannot lead men or that females are less superior to men [23]. As a result, the females have been side-lined more, especially on matters to deal with the administration and other leadership positions. For instance, in African tradition, women are not part of the justice board, which resolve conflict in the community. This implies that women cannot solve the problems which society is facing effectively. It is from this background that many leaders in the companies, be it formal or informal perceive women to be inferior to men. That is because; OECD propounds that tradition plays a very critical role in shaping how human beings think and reason regarding various issues [26]. For instance, if one's tradition has been that male children should not participate in carrying out kitchen house chores such as cooking, sweeping and cleaning, decorating and watering the garden. Then such an individual will find it surprising to see another family from a different tradition engaging the male child in the kitchen house chores. Consequently, a person whose tradition teaches that the responsibility of the females is restricted at home doing house chores, will not engage the females in the professional work, no matter how qualified the female may be. As a result, London Business School (LBS) adds that females are mainly engaged in positions which resemble the responsibilities of the house chores, such as sweeping the offices, cooking for the workers and welcoming the people on the reception [22].

On the other hand, the World Bank explains that for individuals whose tradition does not separate between boys and girls [31]. This means that both girls and boys are given equal responsibilities with regards to house chores. Such people will grow up knowing that women are equal to men. There is nothing a man can do which a woman cannot do, as long as that thing is a gender role in nature. It is from this thinking that we have observed women doing the duties which are dominated by men such as driving public vehicles, repairing vehicles, becoming engineers and even working as transport officers, commonly known as Conductors in Zambia.

Hence, Johnsson-Latham adds that the people who are raised in such a tradition, find it very easy to engage and work with females at any level of the hierarchy [19]. For instance, in some companies, the Chief Executive Officer (C.E.O) who are appointed are females, implying that the company believes that the females have the same capacity to deliver a desirable result, just like men can do. Sometimes women even perform better than men. It is from this perspective that the Zambian President Mr Edgar Chagwa Lungu (ECL) decided to appoint a female as his Vice President of the Republic of Zambia.

Cuberes and Teignier suggest that companies with gender imbalance are lack of innovations, from their employees [16].
That is because having a majority of gender at a company is like promoting the same kind of thinking at the company. For instance, if the majority of the employees at a company are men, then the majority of the ideas will be originating from men. Consequently, the ideas from females will be overshadowed a situation which results in the limited kind of thinking or solving problems. Besides, Tzannatos argues that this is worsened by the principles of democracy, where only the ideas of the majority are being considered [30]. For instance, if the majority of the men don't recognise the need to give a bed rest to females who are experiencing menstrual pains and other problems, then such initiatives cannot come into existence.

From the literature reviewed, there is no research which focused on the gender imbalance in the administrative positions, particularly on the education sector. Furthermore, all the information which has been reviewed relates to the foreign countries, there is no clear information on the gender gaps in Zambian contexts, particularly on the current situation. Thus, this research seeks to contribute to this knowledge gap which exists in the literature. Consequently, illicit activities such as prostitution, theft and spreading of sexually transmitted infections (STIs) seem to be enhanced with gender imbalance. For this reason, the literature has emphasised that there is need for the government and other relevant authorities to formulate and implement policies which are gender-sensitive so that the gender gap could be gradually reduced.

\section{Methodology}

\subsection{Research Design}

Research design is a formal plan of action for a research project. A mixed-method design comprising both quantitative and qualitative research designs was used for this study [11]. The quantitative approach was used to assess the extent of gender gaps in administrative positions of selected educational institutions. Quantitative data, on the other hand, provided an in-depth understanding of the current research problem at hand.

\subsection{Target Population}

The target population were administrators such as College Principals, Deputy College Principals, Registrar, Deputy Registrar, Human Resource Manager, Deputy Human Resource Manager, Head-teachers, Deputy Head-teachers, Head of Departments, Accountants and Secretary from each selected educational institution which is found within Lusaka District of Zambia. This was to conduct a comparative analysis; so that this research could establish the extent to which these sectors adhere to equality and equity [27].

\subsection{Study Sample}

In this study, the sample comprised seventy-eight (78) respondents. This comprised forty-eight (48) administrative officers from six educational institutions that are eight (8), 
administrative officers, from each institution. While 30 respondents were sampled from non-administrative officers, five non-administrative officers were sampled from individual educational institutions. The distribution of respondents was set in that manner so that the representativeness of the views, knowledge and experiences of the respondents could be well captured. This was a reasonable sample size for both quantitative and qualitative study because it provided the data needed as it fulfilled the requirements of efficiency, representativeness, reliability and flexibility [7].

\subsection{Sampling Techniques}

A sampling procedure is a plan that explains how the participants for the study will be selected from the population [8]. The study employed a mixture of probability and nonprobability sampling techniques.

\subsection{Non-probability Sampling Techniques}

The study made use of non-probability sampling technique, precisely the purposive sampling technique. Purposive sampling was employed to select administrative officers in educational institutions. In this sampling technique, the researcher targets a group of people believed to be reliable for the study and people with reliable information or data [4-6].

\subsection{Probability Sampling Technique}

The study also made use of probability sampling technique, precisely the simple random sampling technique. Simple random sampling technique was employed to select 30 nonadministrative officers from the educational institutions. Thus, for this sampling technique to be successful, the researcher collected a list of names for all non-administrative officers at each selected educational institution and then conducted a raffle draw for the names to be engaged in this research. Meaning that one (1) name was picked after shuffling the names; until five (5) names were sampled from each institution. Leany explains that all the researcher needs when using simple random sampling is a small, clearly defined population to use [21]. Thus, this provided each respondent with an equal chance of inclusion in the study sample. Having provided the sampling procedure for this study, we now discuss data collection methods in the next section.

\subsection{Instruments}

This study is both quantitative and qualitative [28]. For this study, two research instruments were used to collect the required information from the respondents, and these were: questionnaire and Semi-structured interview [9]. The questionnaire was used with the College Principals, Deputy Principals, Registrar, Deputy Registrar, Human Resource Manager, Deputy Human Resource Manager, Head-teachers, and Deputy Head-teachers (See appendix 1 for detail). A questionnaire is a tool that provides higher levels of objective information about actual behaviour (McMillan \&
Schumacher, 1993). Moreover, questionnaires are useful because some behaviour involves habitual routines of which people are hardly aware [24]. Semi-structured interviews were used with the Heads of Departments, Accountants and Secretary. The rationale of the interviews with the Heads of Department, Accountants and Secretary was to have an indepth understanding, opinions, and views on the causes of gender gaps in administrative positions of selected educational institutions and the effects of gender gaps in the operations of selected educational institutions. Merriam [24] argues that data collected by this method is relatively reliable and allows respondents to respond to an issue freely and allows the researcher to gather in-depth information.

\subsection{Data Collection Procedure}

As indicated by Merriam, data collection procedure describes and justifies all data collection methods, tools, instruments, and procedures, including how, when, where and by whom data is collected with proof of facts [24]. In line with such guidance, the researchers first obtained an introductory letter from the school. Also, permission to gather information from the respondents was sought [9].

\subsection{Method of Data Analysis}

The data that was collected using questionnaires were analysed using Microsoft Excel and SPSS version 20 to produce outputs such as frequency tables, distribution tables, pie charts and bar charts. Qualitative data that was collected mainly from interviews was analysed thematically. This enabled identification of key ideas within the data collected and for its usefulness in analysing open-ended data from the interview transcripts [10]. During analysis, data recorded from interviews were transcribed, edited, coded, categorised and tabulated [24].

\subsection{Ethical Considerations}

Informed consent was sought from all participants. All the participants were made aware of the nature and purpose of the study and were informed that their participation would not affect their status in the institution and school in any way. The participants' right to privacy and confidentiality was respected [29]. To guarantee the anonymity of participants, pseudo names were used instead of actual ones. The study findings were also shared with the participants. The researchers also adhered to various fundamental ethical principles namely; honesty, objectivity, integrity, carefulness, openness, confidentiality, responsible publication, respect for colleagues, social responsibility, non-discrimination, competence and legality to strive to promote social good and prevent social harm while conducting this research [14].

\section{Presentation and Discussion of Findings}

The research considered the distribution of administrative 
positions amongst the males and females so that this research could be informed if the distribution was normal or skewed towards a particular gender. To that effect, this research considered to investigate the following aspects, for the deeper understanding to be achieved.

\subsection{Distribution of Administrative Positions}

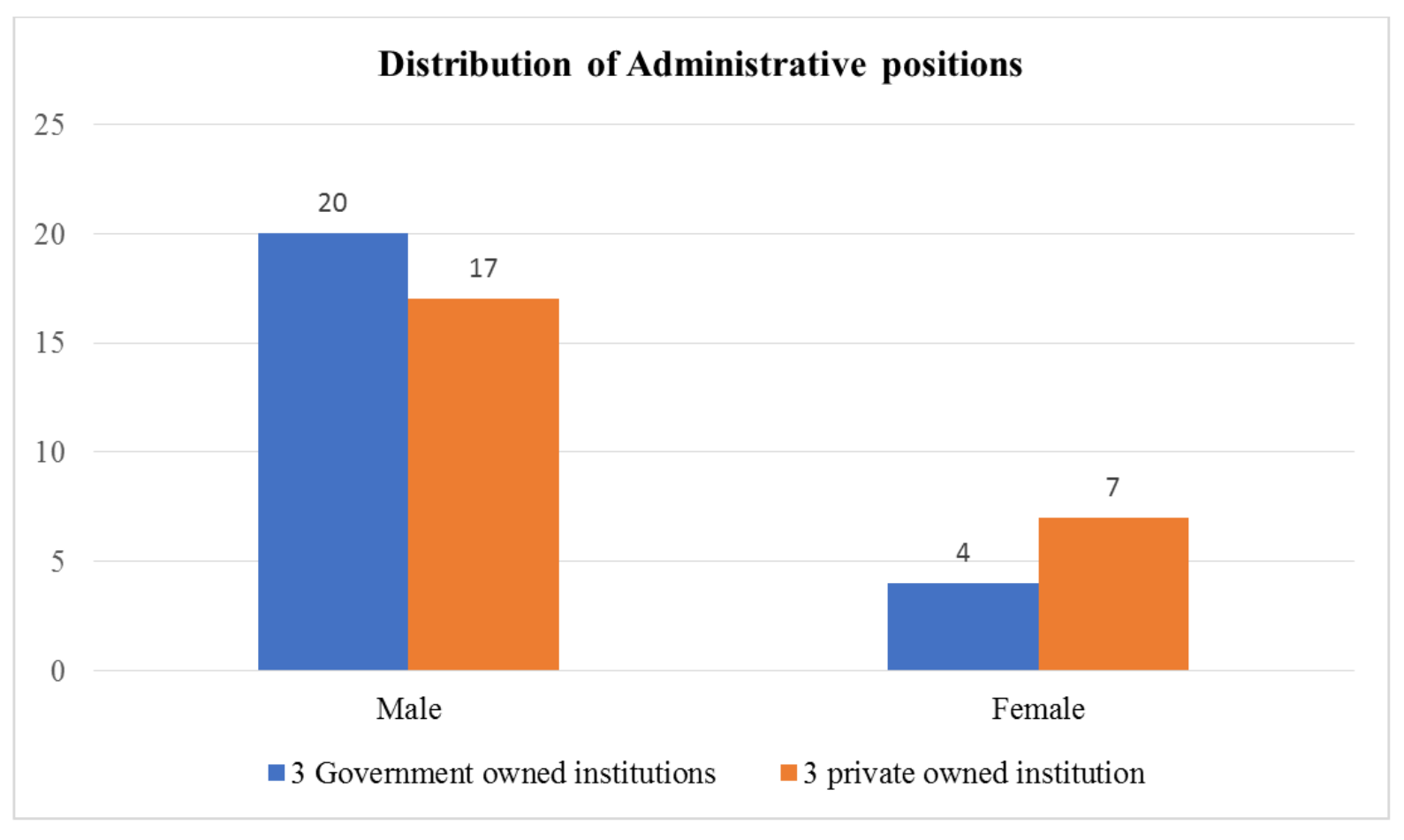

\section{Source: Field data}

Figure 1. Distribution of Administrative positions amongst males and females.

The findings in Figure 1 above show that the governmentowned educational institutions engaged more males in administrative positions than females. That was because out of the total of 24 administrative positions (8 administrative positions from each institution) males in public institutions occupied 17 of them, and this represented $71 \%$ of the total administrative positions in public institutions. Hence, only seven administrative positions were occupied by female administrators and this represented $29 \%$ of the administrative positions in public institutions were occupied by female administrators. Besides, private institutions also had more males who were engaged in administrative positions than females. That is because, out of 24 administrative positions, 14 of them were occupied with males, and this represented $58 \%$. Thus, ten administrative positions were engaged by female administrators, and this represented $42 \%$. Therefore, this research revealed that both public and private institutions tended, allowing gender gaps in their administrative positions. That is because both of them have more male administrators than female administrators.

Furthermore, these results were consistent with the findings which emanated from the interviews as indicated by the following verbatim:

There are more males in administrative positions because many males are creative and hardworking; these attributes make it suitable for male administrators at the company. This is because they can use their creativity to come up with great ideas that are necessary for the growth of an institution. (Headteacher, MoGE)

Furthermore, another respondent revealed that: "It is inappropriate for the females to be put in an administrative position, which is because their male subordinates could be feeling intimidated whenever their female superiors give them the tasks."

These findings were presented according to the characteristic findings on the educational institutions so that a clear picture of how the distribution was, amongst different learning institutions could emerge. Thus, the first three (3) institutions were sampled from government-owned institutions. Thus, they were coded as A, B and C. While the last three (3) institutions were sampled from private-owned institutions, and they were labelled as $\mathrm{X}, \mathrm{Y}$ and $\mathrm{Z}$.

\subsection{Causes of Gender Gaps in Administrative Positions}

This research considered to examine the root causes of gender gaps in administrative positions, this was important because the policymakers in the Ministry of Gender depends on such results for them to come up with well informed and comprehensive policies which will produce the desired results that will stand a test of time. Thus, the interviews revealed the following factors, presented in Table 1 below, as the contributors to the gender gap in administrative positions. 
Table 1. Causes of the Gender gap in Administrative positions.

\begin{tabular}{lll}
\hline Factor & Frequency & Percentage (\%) \\
\hline Lack of clear policy on recruitment and promotion of administrative officers & 48 & 100 \\
Lack of affirmative action during recruitment and promotion process & 48 & 100 \\
Stereotyping of administrative positions & 38 & 79 \\
Lack of gender sensitisation & 19 & 40 \\
Lack of confidence & 31 & 65 \\
Limited role models & 26 & 54 \\
Low level of education and administrative experience amongst females & 30 & 63 \\
Being overwhelmed with household responsibilities & 10 & 21 \\
\hline
\end{tabular}

Source: Field data (2019)

The findings of this research, as indicated in Table 1 above revealed that there are two (2) significant causes of gender imbalance amongst the distribution of administrative positions. All the administrative officers revealed that it was not very clear on the process through which the institutions recruited and promoted the officers. This was further backed by the following verbatim which came from one respondent as indicated below;

The reason why I am acknowledging that the criteria are not very clear is that, during the recruitment or promotion process, some two (2) more people. Both male and female may possess the same qualifications such that if the recruitment or promotion process is objective enough, it could be very challenging to pick up one individual from the individuals who seem to be the same. Unfortunately, in many cases, the male candidate is the one who is mostly preferred. Surprising enough is that even the female staff who are usually present in the recruitment or promotion board also prefer to engage the male candidate, unlike the female candidate. Thus, in light of the above scenario. The recruitment and promotion process is usually very subjective, such that one would wonder why one individual may be recognised over another.

One leader in the MoGE had this to say:

In my own opinion, during the recruitment process, when it happens that some people have relatively the same qualifications. I suggest that the institutions should be assessing those candidates further by giving them aptitude tests or even engaging them in temporal practical work so that the best candidate could be recruited. This is important because the majority of the gender which is being employed will most likely be the majority of the top management of an institution. (Head of Department, MoGE)

Furthermore, the findings in Table 1 above also revealed that the lowest contributor to gender gaps in institutions was the claim that most females are overwhelmed with social responsibilities such as taking care of children and other family members. For that reason, another respondent revealed the following view, which is presented in the verbatim given below:

Females cannot manage to handle most administrative positions, mainly because these positions require adequate time and a free mind for planning. Unfortunately, because many females are busy with household chores, they reach their respective workplaces already tired. As a result, the work output is negatively affected. To that effect, many females tend to work less, and they also have a higher frequency of sick leaves. Besides, the females may not always be at the workplace, which is because when they become pregnant, they are entitled to maternity leave which lasts for several months. It is for these reasons that many institutions wouldn't want to recruit females in administrative positions. (Secretary, MoGE)

Besides, this research indicated the distributions of the views amongst the six (6) institutions which were sampled so that clarity could be achieved. Thus, all 48 respondents were asked to identify the causes which contributed to gender gaps in different institutions. Therefore, the factors which were revealed from each institution were calculated out of the total of 8 respondents (administrative officers).

The results indicate that most respondents disagreed that females were not appointed into administrative positions because of being overwhelmed with social responsibilities. The verbatim supported this from the interviews which were conducted as indicated below;

It is not logical that females are usually stressed with household chores before they could resume their professional work. That is because the new trend now indicates that most of the females who are working have either employed the house maids or they live with their relatives who can help them to handle household duties in their absence. This means that females are as free as male employees. (Accountant, MoGE)

\subsection{Effects of Administrative Gender Gaps on Ordinary Employees}

This research considered to investigate the possible effects which gender gaps may have on the working conditions of the institutions. That is because the researcher wanted to establish if gaps in administrative position had any impact or not. If they do, then it was necessary to understand how gender gaps negatively affected the working conditions of the institutions. Thus, the findings from all the six (6) institutions were summarised in Table 2 as illustrated below; 
Table 2. Effects of Gender Gaps in Administrative position.

\begin{tabular}{lll}
\hline Affected Areas & Frequency & Percentage (\%) \\
\hline Enhanced male dominance and gender-based crimes & 21 & 70 \\
Inadequate creativity & 16 & 53 \\
Formation of gender imbalanced policies & 28 & 93 \\
Female employees lack a role model & 14 & 47 \\
Female employees lack confidants & 08 & 27 \\
Widened income gaps & 25 & 83 \\
Enhanced vulnerability amongst women & 05 & 17 \\
\hline
\end{tabular}

Source: Field data (2019)

The findings in Table 2 above indicates that gender gaps in administrative positions mostly affects the formation of policies. Most of the guidelines which are formulated are not gender-balanced, which is because they lack female representation. Thus, out of the total of 30 respondents, 28 of them (93\%) indicated that gender gaps lead to the formulation of gender-biased policies. This was further supported by the verbatim which was extracted from the interviews as shown in words;

When the majority of the Administrators are males, then they are most likely to neglect the concerns of the female employees such that the employees feel unsatisfied to work in such environments. As a result, their work output is negatively affected." (Head of Department, MoHE)

Furthermore, out of the total of 30 respondents, 08 of them $(27 \%)$ indicated that the employees whose gender is not well represented in the administrative positions lack the confidants in their workplaces. Thus, they don't have the people in authority whom they can share their socioeconomic and psychological problems with. These findings were in line with the views of the respondents above.

While the results in Table 2 above also indicated that the lowest effect which gender gaps had on the operations of the institutions was enhanced vulnerability amongst the females. That is because when most of the females are not in administrative positions, they are more likely to get little income. As a result, their level of income is usually lower. This was further supported by the verbatim, which represented the views of one respondent, as shown below:

Most of the females who are employed in different institutions, whether private or government-owned institutions are usually offered low hierarchical positions which have low income attached to them. As a result, many females are not economically stable. Thus, they depend on males, when they are trying to solve most of their economic problems, thereby enhancing male dominance. (Accountant, MoHE)

The distribution of the views amongst ordinary employees was further represented according to individual institutions. This was done so with the view of understanding the effects of gender gaps across government and privately owned institutions.

The findings revealed that the majority of the employees who have been engaged in Administrative positions are male. That is because, out of the total of 48 administrative positions sampled, from six (6) institutions, both private and government-owned, 31 of them were males, and this represented $65 \%$ of the total Administrators. While only 11 Administrative officers were females, and this represented $35 \%$ of the total Administrators. This research also revealed that the majority of the institutions, more especially government-owned institutions had the male Administrators employed in the senior-most positions of the institution, while the females were mainly employed at deputy level and in many cases, the females where employed in low hierarchical positions such as secretarial level. Thus, this research has established that low levels of education and experience significantly affected the engagement of females in administrative positions. That is because most of the females couldn't qualify for higher positions which equally require higher academic qualifications. Hence, this research also indicated that gender gaps negatively affected the operations of the institutions, which is because most of the policies which are formulated are not gender-balanced. Furthermore, the females lacked role models and confidants whom they could shares their problems with.

These findings were in agreement with the views of FAWEZA, which observed that the girl-child is discriminated against in many aspects of humanity, from the earliest stages of life, through childhood into adulthood [15]. In terms of education, Kelly highlights that discrimination includes; unequal access, poor performance, early dropout and low enrolment in higher education which means that these factors discourage the females from actively participating in the learning process of formal education [20]. In this context, low attainment of education prevents the females from being actively engaged in an administrative position. That is because they tend to possess academic qualifications, which are below the minimum requirements.

Going by the findings represented this research agreed with the claim which is being made by radical feminist theory. The theory claims that there is patriarchy in society; it implies that males oppress females through dominating in influential positions of society. In this context, the males equally dominated in the administrative positions of the educational institutions; it is the duty of all administrators at any given institution to make the policies and other regulatory plans. Hence, when the majority of the administrative officers are males, just like in this context, the views of the females cannot be heard. 


\section{Conclusions}

This study has revealed that the extent to which there are gender gaps in administrative positions of educational institutions is very significant. That is because the number of male administrative (31) officers is slightly double the numbers of female administrative (17) officers. This meant that the recruitment and appointment of the administrative officers in educational institutions was very biased towards the males. To that effect, $83 \%$ of the senior-most administrative officers were males. This meant that only $17 \%$ of the seniormost administrative officers were females. Thus, the females were mainly engaged in deputy administrative positions and more in a secretarial position. This indicated that many educational institutions, more especially government-owned institutions, were more gender-biased. That is because out of the three (3) government-owned institutions which were sampled, all of them were headed by male College Principals. At the same time, the private-owned educational institutions revealed that they were making efforts in engaging the females in administrative positions. That is because out of the three (3) private-owned institutions, two (2) of them were headed by male College Principals, but a female College Principal headed one (1) of them.

\section{References}

[1] Adetunde, I. A., and Akensina, A. P. (2008). Factors affecting the standard of female education: A case study of senior secondary schools in the Kassena- Nankana district. Journal of social sciences, 338-342.

[2] Bergmann, B. (1971). The effect on white incomes of discrimination in employment. Journal of Political Economy.

[3] Catalyst, K. (2007). The bottom line. Corporate Performance and Women's Representation on Boards, 1-23.

[4] Chipindi, F. M. (2009). The quality-quantity trade-off: Implications of expanded enrolments at two of Zambia's public universities (Unpublished master's dissertation). University of Zambia, Lusaka. http://dspace.unza.zm/handle/123456789/348.

[5] Chipindi, F. M. (2017). Neoliberal governmentality, responsibilization and the deepening of academic tribalism in the Zambian academy: A commentary. International Journal of Multi-Disciplinary. Research. ISBN (online): 3471-7102. https://www.researchgate.net/publication/320979075 Neolibe ral_governmentality_responsibilization_and_deepening_acade mic_tribalism_in_the_Zambian_academy_a_commentary.

[6] Chipindi, F. M. (2018). Negotiating professional identities in a liberalized Sub-Saharan economy: A case of University of Zambia faculty (unpublished $\mathrm{PhD}$ dissertation). University of Minnesota, Minneapolis.

[7] Chipindi, F. M. \& Doyle, H. (2017). Zambia scoping study. In H. Doyle, A. M. Barrett \& A. Reeves (Eds.), Improving the quality of teaching in secondary education: scoping studies for Zambia, Malawi, Tanzania, Côte D'Ivoire and Senegal (pp. 4-32). Bristol: Bristol University. http://dspace.unza.zm/handle/123456789/6744.
[8] Chipindi, F. M. \& Chipindi, S. J. (2016). Trade-off issues in teacher education at the university of Zambia: Growing student numbers and the quality of teacher education processes. International Journal of Teaching and Learning in $\begin{array}{llll}\text { Africa } & 3 & \text { (1), }\end{array}$ http://dspace.unza.zm/handle/123456789/6745.

[9] Chipindi, F. M. \& Vavrus, F. (2018). The ontology of mention: Contexts, contests, and constructs of academic identity among the university of Zambia faculty. FIRE: Forum for International Research in Education, 4, (3), 102-116. ISSN: 2326-3873.

[10] Cuberes, D., and Teignier, M. (2012). Gender gaps in the labour market and aggregate productivity. Department of Economics, 2012-2017.

[11] Daka, H., Chipindi, F. M. \& Mwale-Mkandawire, M. (2020). The relationship between assessment practices and students' academic performances. A case of undergraduate students at the medical school of the university of Zambia, 2008 - 2016. Zambian Journal of Educational Management, Administration and Leadership, 1, (1), 143-156. ISSN: 2706-7416 (Print). http://dspace.unza.zm/handle/123456789/6742.

[12] Daley-Harris, S. (2006). State of the microcredit summit campaign report 2004. Washington D. C: Microcredit Summit Campaign.

[13] Energia. (2007). Where Energy is Women's Business. National and Regional Reports from Africa, Asia, Latin America and the Pacific, 1-11.

[14] Ethical Trading Initiative (ETI). (2003). Women workers. Are Current Practices Enough to Address Discrimination in the Workplace? 1-9.

[15] Forum for African Women Educationalist. (1996). Beyond Beijing: A summary of the global and African region platforms for action with a focus on education. Fourth World Conference on Education, 1-39.

[16] Gender in Development Division. (2000). National gender policy. Lusaka: Government Printers.

[17] Gender in Development Division. (2004). Zambia' progress report on the implementation of the Beijing Platform for Action. Lusaka: Government Printers.

[18] ILO/UNDP. (2012). Rethinking Economic Growth: Towards Productive and Inclusive Arab Societies. Beirut: ILO.

[19] Johnsson-Latham, G. (2006). Do women leave a smaller ecological footprint than men? Stockholm: Swedish Ministry of Sustainable Development.

[20] Kelly, M. J. (2006). The origins and development of education in Zambia-From pre-colonial times to 1996. Lusaka: Image Publishers.

[21] Leany, C. (2004). Social Science Research. London: Oxford: Sage.

[22] London Business School (LBS). (2007). Innovative potential. Men and Women in Teams, 1-34.

[23] McKinsey, C. (2007). Women matter: Gender diversity. $A$ Corporate Performance Driver, 1-13.

[24] Merriam, S. B. (1998). Qualitative research and case study applications in education. San Francisco: Jossey-Bass Publishers. 
[25] Organisation for Economic Cooperation and Development [OECD]. (2008). Gender and Sustainable Development. Maximising the economic, social and environmental role of women, 1-80.

[26] OECD. (2007). Aid in support of gender equality and women's empowerment. DAC Members' reporting on the Gender Equality Policy Marker, 2004-2005, 1-36.

[27] Thomas, M. A. M., Serenje-Chipindi, J \& Chipindi, F. M. (2020), Comparing course. syllabi from A to Z: Examining the contexts, content, and concerns for social foundations of education in Australia and Zambia. In A. E. Mazawi \& M. Stack (Eds.). Course Syllabi in Faculties of Education across the World: Bodies of Knowledge and their Discontents (pp 38-50). Sydney: Bloomsbury, ISBN 978-1-3500-9425-3 978-1-3500-9427-7 (online). http://dspace.unza.zm/handle/123456789/6619.

[28] Mbewe. E. G, Matafwali. B, \& Mwanza- Kabaghe. S., (2016). Teachers', pupils' and parents' perceptions on the use of chinyanja as a medium of instruction in selected lower primary schools in Lusaka district, Zambia. International Journal of Humanities Social Sciences and Education, 3, (11), 25-35. ISSN 2349-0373 (Print) \& ISSN 2349-0381 (Online) doi10.20431/2349.0311004

[29] Mwanza-Kabaghe, S. (2015). Preschool, Executive Functions and Oral Language As Predictors Of Literacy And Numeracy Skills In First Grade (Doctoral dissertation, University of Zambia). Retrieved from http://lollenautafoundation.eu/uploads/sylvia-mwanza-phdthesis-comp_-513809989.pdf.

[30] Tzannatos, Z. (2016). Effect of gender inequality in employment and pay in Jordan, Lebanon and the occupied Palestinian territory: Three questions answered. International Labour Organisation, 1-30.

[31] World Bank. (2010). Education data. Washington, D. C: United Nation Educational, Scientific and cultural organization (UNESCO) and Institute for statistics. 